\title{
PLASMA THE FOURTH STATE OF MATTER
}




\section{PLASMA}

\section{THE FOURTH STATE OF MATTER}

\section{A. Frank-Kamenetskii}

Kurchatov Institute of Atomic Energy Academy of Sciences of the USSR, Moscow

Translated from Russian by

Joseph Norwood, Jr.

Assistant Professor of Physics

University of Miami, Coral Gables, Florida 
The original Russian text was published by Atomizdat in Moscow in 1968. The English translation is published under an agreement with Mezhdunarodnaya Kniga, the Soviet book export agency.

Давид Альбертович Франк-Каменецкий

П Л А М А : Ч Т ВЕРТОЕ СОСТОЯ Н И ВЕЩ СТ ВА PLAZMA: CHETVERTOE SOSTOYANIE VESHCHESTVA

(1) 1972 Plenum Press, New York

Softcover reprint of the hardcover 1st edition 1972

All rights reserved. No part of this publication may be reproduced or transmitted in any form or by any means without written permission from the publisher.

Published 1972 by The MACMILLAN PRESS, LTD.

London and Basingstoke

Associated Companies in

New York Melbourne

Toronto Dublin Johannesburg

and Madras

SBN 333136764

ISBN 978-1-349-01554-2

ISBN 978-1-349-01552-8 (eBook)

DOI 10.1007/978-1-349-01552-8 


\section{Foreword}

The idea for this book originated with the late Igor Vasil'evich Kurchatov. He suggested to the author the need for a comprehensive presentation of the fundamental ideas of plasma physics without complicated mathematics. This task has not been an easy one. In order to clarify the physical nature of plasma phenomena without recourse to intricate mathematical expressions it is necessary to think problems through very carefully. Thus, the book did not come into being by inspiration, but required a considerable effort.

The aim of the book is to provide a beginning reader with an elementary knowledge of plasma physics. The book is primarily written for engineers and technicians; however, we have also tried to make it intelligible to the reader whose knowledge of physics is at the advanced-freshman level. To understand the book it is also necessary to have a working knowledge of electricity and magnetism of the kind available in present-day programs in junior colleges.

This book is not intended for light reading. It is designed for the reader for whom plasma physics will be a continuing interest. We have confidence that such a reader will want to broaden his knowledge by consulting more specialized literature. Thus, we not only include simple expressions but also special important terms.

Every scientific discipline has its own language. Before undertaking a journey we must acquire a knowledge not only of 
the geography, but also of the language of the country we intend to visit. It is equally important in the journey to new regions of knowledge that some familiarity with its special language be acquired. Thus, every new term is emphasized (by expansion) when it first appears.

In the American edition of this book we will use the rationalized MKS system of units, which has become increasingly popular in science and engineering in recent years.

The physics of plasmas is a field in which knowledge is expanding rapidly. The size of this book does not allow us to cover everything we should. To mention the work of only some of the workers in this field would be an injustice to the others. Thus, we have decided not to give references or names, except where the names appear in scientific terminology.

The growing science of plasmas excites lively interest in many people with various levels of training. We hope, therefore, that the book will be useful to a broad range of readers.

The author expresses his thanks to friends and colleagues such as S. I. Braginskii, A. A. Vedenov, E. P. Velikhov, V. P. Demidov, E. K. Zavoiskii, B. B. Kadomtsev, I. A. Kovan, V. I. Kogan, M. A. Leontovich, V. I. Patrushev, L. I. Rudakov, V. D. Rusanov, R. Z. Sagdeev, and V. D. Shafranov for their constant interest and many discussions covering the entire range of plasma physics. T. D. Kuznetsov gave invaluable help with the illustrations. 


\section{Contents}

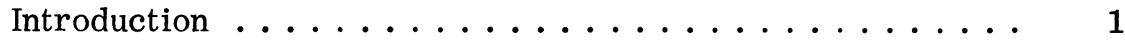

Production of a Plasma ............... 8

Plasma Diagnostics .................. 11

Quasi Neutrality and Charge Separation .......... 18

Polarization of a Plasma . . . . . . . . . . . . 22

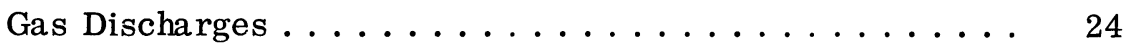

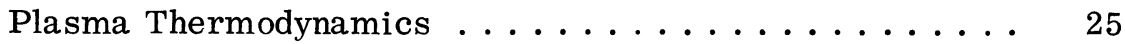

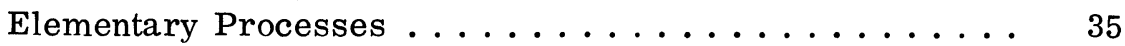

Plasmas and Radiation ................ 36

Equilibrium and the Stationary Ionization States ...... 40

Plasmas as Conducting Fluids . . . . . . . . . . . 44

Field Diffusion and Plasma Diffusion. . . . . . . . 50

Applications of the Conducting-Fluid Model ........ 51

Toroidal Plasma Traps................... 53

Electromagnetic Pumping and Plasma Acceleration ..... 55

Magnetohydrodynamic Flow . . . . . . . . . . . 57

The Two-Fluid Model . . . . . . . . . . . . . 59

Plasma Conductivity in a Magnetic Field . . . . . . . . . 64

Plasma as an Ensemble of Independent Particles....... 66

Drift Motion . . . . . . . . . . . . . . . 68

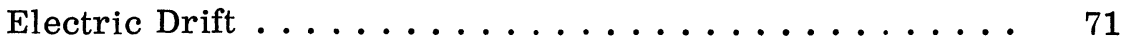

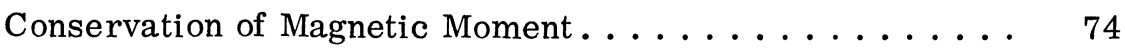

The Adiabatic Traps. . . . . . . . . . . . . . 75

Drift in an Inhomogeneous Field . . . . . . . . . 79

Polarization Drift ................. 83

Rotating Plasmas...................... 85 
The Magnetization Current $\ldots \ldots \ldots \ldots \ldots \ldots$

The Quasi-hydrodynamic Approximation .......... 89

Hydromagnetic Plasma Instabilities ............ 91

Pinch Instability . . . . . . . . . . . . . . 95

Stabilization by Frozen-in Magnetic Fields . . . . . . . 96

Interchange or Flute Instabilities . . . . . . . . 98

Diffusion of Opposed Fields . . . . . . . . . . . 100

Oscillations and Waves in Plasmas . . . . . . . . . . 104

Electrostatic Plasma Oscillations . . . . . . . . . . . . 108

Electrostatic Oscillations with Ions . . . . . . . . . . 110

Plasma Oscillations in a Magnetic Field . . . . . . . . 113

Dispersion near the Cyclotron Frequency . . . . . . . . . 116

Oblique Waves and General Classification of Oscillations . . 119

Propagation of Radio Waves through a Plasma . . . . . . 120

Plasma Resonators and Waveguides ........... 126

Excitation and Damping of Oscillations ........... 130

Shock Waves in Plasmas . . . . . . . . . . . . . . 134

Random Processes. . . . . . . . . . . . . . . 135

The Drunkard's Walk . . . . . . . . . . . . . . . 138

The Mean Free Path and the Collision Cross Section . . . . 139

Collisions with Neutral Particles . . . . . . . . . . . 141

Coulomb Collisions . . . . . . . . . . . . . . . 144

The Establishment of Thermal Equilibrium. . . . . . . . 148

Transport Processes in a Magnetic Field ......... 150

Ambipolar Diffusion . . . . . . . . . . . . . . . 152

A Recent Plasma Experiment. . . . . . . . . . . . . 154

Index ....................... 157 